\title{
UPPER ARM BASILIC VEIN TRANSPOSITION FOR HEMODIALYSIS: WHAT IS THE OPTIMAL TECHNIQUE?
}

\author{
Mohammed Alsagher Alhewy
}

Vascular surgery unit, faculty of medicine- AlAzhar university, Assiut

Corresponding Author:

Mohammed Alsagher Alhewy

E-mail: elsagher2030@yahoo.com

tel: 01000852927

\begin{abstract}
Objective: The brachiobasilic arteriovenous fistula (BBAVF) can be formed in one or two stages. This study examined the failure rates and functional patencies of one-stage vs two-stage brachiobasilic transposition fistulas to compare the two surgical techniques.
\end{abstract}

Patients and methods: 50 BB fistulae (25 single and 25 two-stage) were created over a 3year period (2012-2015). Data including sex, age, dialysis and diabetic status was collected from the case notes. Patency and time to maturity data was collected prospectively from the dialysis unit.

Results: During the study interval, 100 brachiobasilic transpositions (50 one-stage and 50 two-stage) were performed in 100 patients. Patients undergoing the two-stage procedure tended to be older (mean 49 vs 53 years; $\mathrm{P}=0.8$ ). The two-stage $\mathrm{BBAVFs}$ had significantly better primary ( $88 \%$ vs $92 \% ; \mathrm{P}=0.58$ ), and secondary functional ( $92 \%$ vs $96 \% ; \mathrm{P}=0.508$.) patencies. Pre-HD fistula has better patency than post-HD fistula $(100 \%$ vs $90 \% ; \mathrm{p}=0.015$ )

Conclusion: This study describes a series of BBAVFs and makes comparison between the one-stage and two-stage operations. Significantly improved overall functional patency is demonstrated for the two-stage operation.

Keywords: Brachiobasilic, Fistula, Transposition.

\section{INTRODUCTION}

Since nce the creation of the first autogenous Arteriovenous (AVF) fistula in 1966, ${ }^{(1)}$ arteriovenous fistulae has become common vascular procedure. Many researchers have documented multiple benefits of AVF creation which include lowered morbidity, mortality, and prolonged survival, for patients. ${ }^{2}$, 3 The use of the basilic vein for an autogenous fistula creation is often considered a complex vascular access procedure, usually involving a general anesthetic and significant surgical dissection. However, when other simple fistula options are exhausted, the basilic vein, lying deep and protected from damage by venipuncture, makes an excellent hemodialysis conduit. The brachiobasilic arteriovenous fistula (BBAVF) was first described by Dagher ${ }^{(4)} 1$ in 1976. Several modifications of the initial operation have been developed in the years since then. However, the basic principle is to superficialize the basilic vein and make it amenable to needle puncture. The BBAVF can be formed in one stage or two stages. To date, limited and conflicting data exist regarding primary failure and the patency rates of one-stage and two-stage procedures. (5-11) each procedure has advantages and disadvantages. The one-stage procedure offers the benefits of a single operation with earlier functional patency and possible shorter duration with a central venous catheter. The advantage of a two-stage procedure is the ease of mobilization of a larger "arterialized" vein, rendering it less susceptible to torque and devascularization during mobilization. ${ }^{(12)}$ If surgical revision for postanastomotic stenosis is required, this is easily performed at the second stage. In case of early failure, the patient is spared a general anesthetic and significant surgical dissection.

necessitates two operations, which may affect operating theater capacity and delay acquisition of permanent access. (12) So I performed a prospective randomized study to assess whether creating brachiobasilic arteriovenous fistula by a single or a two stage method provides a better outcome as regard patency and feasibility. 


\section{PATIENTS AND METHODS}

This prospective randomized study was subjected in patients with end stage renal disease (ESRD) who could not achieve radiocephalic or brachiocephalic arteriovenous fistula because of unsuitable cephalic vein or previously failure of these accesses.

The study was performed on a group of patients with ESRD, Patients were recruited from the Vascular Outpatient Clinic of AL-Azhar University Hospitals and enrolled during the period between April 2012 and April 2015.patients were subjected to routine history taking, clinical examination, laboratory and radiological investigations. Patients were classified into two groups in a randomized manner:

Group A: included 25 patients who were operated by primary transposed brachiobasilic arteriovenous fistula.

Group B: included 25 patients who were operated by staged transposed brachiobasilic arteriovenous fistula.

\section{Inclusion and exclusion criteria}

Patients between 18 and 70 years of age of both genders, with CKD already on hemodialysis or with anticipated hemodialysis were eligible for inclusion. Patients were excluded if they were unwilling to participate and/or not consenting, had a suitable cephalic vein to construct a radio-cephalic or brachiocephalic fistula, the basilic vein was unsuitable for use because it measured less than $2.5 \mathrm{~mm}$ or had intrinsic lesions on Duplex ultrasound, or the basilic vein was already enlarged by a previous wrist or elbow arteriovenous fistula draining into the basilic vein on Duplex ultrasound, as detailed below. Preoperative vessel mapping was performed with Duplex ultrasound and selective use of venography, with the minimum and maximum diameter of the basilic vein being recorded, after application of a tourniquet, including the diameter of the medial antecubital (basilic) vein. Particular attention was made to identify drainage patterns of previous AVFs (radio-cephalic and brachiomedian cubital) leading to enlargement of the basilic vein in order to exclude these patients from the study and also to completely map the basilic vein in order to choose the incision site.

\section{Description of Surgical Technique:}

Group A: Under general anesthesia and after antibiotic prophylaxis a 2-cm transverse incision is made proximal to the antecubital crease to expose the brachial artery. An interrupted or continuous longitudinal incision is made at the medial side of the upper arm and is made to dissect the basilic vein (Fig. 1). The basilic vein is mobilized along the entire upper arm, and visualized tributaries are ligated. The basilic vein is transected as distal as possible. Care must be taken to preserve the medial brachial cutaneous nerve as it runs close to the basilic vein. A bulldog clamp is placed at the proximal end of the basilic vein, and either saline or dilute papaverine is gently injected into the basilic vein to dilate it. Care must be taken to avoid overdistention, as this may lead to intimal injury and resultant intimal hyperplasia. The vein is (i) transposed to the anterior arm with the use of a tunneling device (fig 2), (ii) transposed to the anterior upper arm under a lateral flap of skin. All methods attempt to place the fistula approximately $6 \mathrm{~mm}$ beneath the skin for ease of dialysis access. If a tunneling is chosen, it must be performed prior to the brachial artery anastomosis. A subdermal tunnel with a diameter of at least $10 \mathrm{~mm}$ is created lateral, anterior, and superficial to the basilic vein position in the upper arm. The basilic vein is pulled through the tunnel with care not to kink, twist, or traumatize the vein. Alternatively, a skin flap is created in the subcutaneous tissue laterally and anteriorly, and the deeper layer is closed over the native basilic vein site to protect and displace the fistula from the deeper structures including the artery and medial antebrachial cutaneous nerve. The basilic vein fistula is then positioned in the lateral portion of the subcutaneous pocket. The underlying subcutaneous tissue is closed beneath the vein, and the overlying skin is closed. The role of heparinization is controversial. Either heparin can be given systemically or dilute heparin is injected directly into the basilic vein and the brachial artery is clamped. A 6$\mathrm{mm}$ arteriotomy is made in the side of the 
brachial artery, and an end-to-side anastomosis is performed using running 6-0 prolene suture without excessive tension on the basilic vein in its new position.

Group B: In the two-stage procedure, initially under local anesthesia the basilic vein and brachial artery are exposed via a similar two-cm incision just proximal to the antecubital crease. The vein is anastomosed to the artery without initial superficialization. Following a variable time period of four to six weeks, I assess the maturity of the vein by the use of duplex scan, and if the vein is mature sufficiently I refer the patient for the second stage. If the vein had not matured sufficiently, I postpone the second operation with regular monitoring of the patients. Once mature, basilic vein is then mobilized in the second stage of the procedure to transpose to the anterior upper arm under a lateral flap of skin. All second operations were carried out as an inpatient procedure under local anesthesia with use of general anesthesia in selected cases. I prefer to use drains in single stage operations and at second operation of two stage procedure. Drains were removed within one to two days. All arteriovenous fistulae were scanned for one to two months after creation, Maturation was determined and defined by a minimum vein diameter of 5 $\mathrm{mm}$, a flow rate of greater than $500 \mathrm{ml} / \mathrm{min}$ and assessment clinically that the fistula was suitable for cannulation.

Figure 1 basilic vein after mobilization and flushing with heparinized saline.

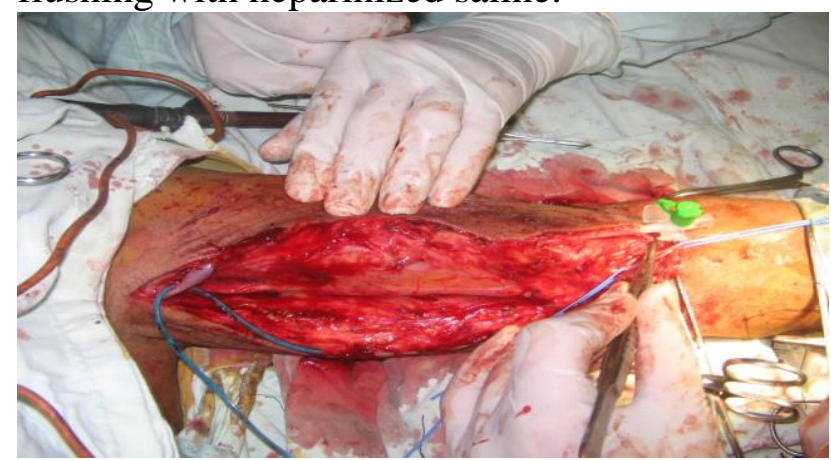

Figure 2 Basilic vein flushing to detect kink or rotation after passage in the tunnel.

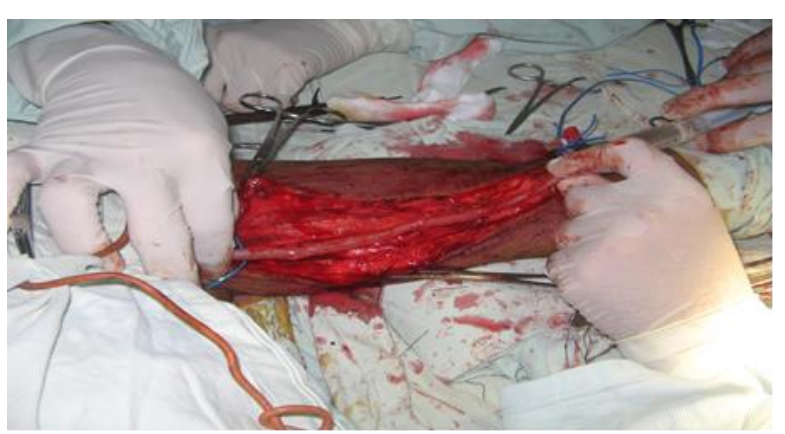

\section{Post-operative follow-up:}

Clinical follow-up was performed during the follow-up period (12 month) for Primary patency, Complications which include: Bleeding, Early thrombosis, late thrombosis, Infection, Pseudo aneurysm, vascular steal, venous hypertension and Seroma. Follow -up data was obtained from patient's evaluation during visits, dialysis units and nephrologists.

\section{Statistical analysis:}

Data were analyzed using Statistical Program for Social Science (SPSS) version 20 and Microsoft Excel 2013. Quantitative data were expressed as mean \pm standard deviation (SD). Qualitative data were expressed as frequency and percentage.

The following tests were done:

- Independent-samples t-test of significance was used when comparing between two means.

- Chi-square $\left(\mathrm{X}^{2}\right)$ test of significance was used in order to compare proportions between two qualitative parameters.

- Probability (P-value)

- P-value <0.05 was considered significant.

- P-value <0.001 was considered as highly significant.

- P-value >0.05 was considered insignificant.

\section{RESULTS}

Fifty patients had a brachiobasilic fistula created over a three year period between April 2012 and April 2015 at AL-Azhar University Hospitals. The characteristics of the two groups are summarised in Table 1 . Of the 50 patients, $25(50 \%)$ had their fistula created as a single stage and $25(50 \%)$ had their AVF created as a two stage procedure. Of the two stage patients, there was a median 2.5 months (range 1.5-3.5 months) delay between the two operations. This delay reflected the variable time needed for maturation of the vein. The second stage of all two stage patients, 
excluding one, was completed. The BB fistula was the first form of vascular access in 7 out of 25 single stage patients, and this was statistically lower than 15 of the 25 two stage patients $(\mathrm{p}=0.008)$. There was an $88 \%$ functional patency rate at 6 weeks for all the single stage fistulae. This was comparable to $92 \%$ in the two stage fistulae $(\mathrm{p}=0.58)$. The three single stage fistulas that were not patent at 6 weeks, one (4\%) had failed to mature and two (8\%) had thrombosed. Three (12\%) single stage patients underwent revisional surgical or radiological procedures for failing fistulae. One patient (4\%) had a revision of their anastomosis, one patient (4\%) underwent thromboembolectomy and one patient (4\%) had percutaneous angioplasty. Similarly two (8\%) two stage patients had revision procedures performed on their fistulae and one (4\%) underwent thromboembolectomies, and a further one (4\%) had percutaneous angioplasty.
Table 1 clinical characteristics of patients

\begin{tabular}{lccc}
\hline & Stage 1 & Stage 2 & P-Value \\
\hline $\begin{array}{l}\text { No of } \\
\text { AVF }\end{array}$ & 25 & 25 & \\
\hline $\begin{array}{l}\text { Age } \\
\text { (range) }\end{array}$ & $\begin{array}{c}49 \\
(18-62)\end{array}$ & $\begin{array}{c}53 \\
(18-70)\end{array}$ & $0.8(\mathrm{NS})$ \\
\hline Right: left & $10-15$ & $8-17$ & $0.25(\mathrm{NS})$ \\
\hline Diabetic & 5 & 9 & $0.13(\mathrm{NS})$ \\
\hline M:F & $14-11$ & $13-12$ & $0.47(\mathrm{NS})$ \\
\hline $\begin{array}{l}\text { Pre HD: } \\
\text { post HD }\end{array}$ & $8-25$ & $12-25$ & $0.18(\mathrm{NS})$ \\
\hline
\end{tabular}

No. of AVF, number of AVF created; M: F, Male: Female; Pre-HD: Post-HD, fistula created before commencing haemodialysis: fistula created after commencing dialysis; NS, not significant.

Table 2. Functional patency rates at 6 weeks.

\begin{tabular}{|c|c|c|c|}
\hline & functioning & Non functioning & p-value (Significance) \\
\hline Stage 1 & $22(88 \%)$ & $3(12 \%)$ & $0.58(\mathrm{NS})$ \\
\hline Stage 2 & $23(92 \%)$ & $2(8 \%)$ & \\
\hline Created pre HD & $19(95 \%)$ & $1(5 \%)$ & $0.015(\mathrm{~S})$ \\
\hline Created post HD & $26(86.5 \%)$ & $4(13 \%)$ & \\
\hline diabetic & $14(87 \%)$ & $2(12.5 \%)$ & $0.410(\mathrm{NS})$ \\
\hline Non diabetic & $31(91.2 \%)$ & $3(8.8 \%)$ & \\
\hline Diabetic Pre-HD & $10(90.9 \%)$ & $1(9 \%)$ & $0.17(\mathrm{NS})$ \\
\hline Diabetic Post-HD & $6(85.7 \%)$ & $1(14.3 \%)$ & \\
\hline Non-diab Pre-HD & $10(100 \%)$ & $0(0 \%)$ & $0.208(\mathrm{NS})$ \\
\hline Non-diab Post-HD & $19(86.3 \%)$ & $3(13.7)$ & \\
\hline
\end{tabular}

Pre-HD = fistula created before commencing dialysis. Post-HD = fistula created after commencing dialysis. Non-diab: non diabetic.

Secondary patency rates were similar between the two groups with one stage $92 \%$ which was comparable to $96 \%$ of the two stage procedures. This difference was not significant ( $\mathrm{p}$-value $=0.508)$. Clinical characteristics were then examined to assess whether they affected the outcome of the functional patency of the fistulas at six weeks (Table 2). Sex, diabetic status and which arm the fistula was situated were all nonsignificant factors. However when comparing those who had their fistula created before starting dialysis (Pre-HD) with those who had their fistula created whilst on dialysis (PostHD), there were significant differences. Nineteen $(95 \%)$ out of 20 patients who had their fistula created Pre-HD had a patent fistula at 6 weeks compared to $26(86.7 \%)$ out 
of 30 patients who had their fistula created whilst on dialysis had a patent AVF at 6 weeks. The difference was statistically significant $(\mathrm{p}-$ value $=0.015)$. When assessing the differences in long term patency between the two groups, I found that fistulae.

Table3. Functional patency rates at 6 months

\begin{tabular}{lccc}
\hline & functioning & Non functioning & $\begin{array}{c}\text { p-value } \\
\text { (Significance) }\end{array}$ \\
\hline Stage 1 & $23(92 \%)$ & $2(8 \%)$ & $0.508(\mathrm{NS})$ \\
\cline { 1 - 3 } Stage 2 & $24(96 \%)$ & $1(4 \%)$ & $0.01(\mathrm{~S})$ \\
\hline Created pre HD & $20(100 \%)$ & $0(0 \%)$ & \\
\hline Created post HD & $27(90 \%)$ & $3(10 \%)$ & $0.30(\mathrm{NS})$ \\
\hline diabetic & $14(87.5 \%)$ & $2(12.5 \%)$ & $0.205(\mathrm{NS})$ \\
\hline Non diabetic & $33(97 \%)$ & $1(3 \%)$ & \\
\hline Diabetic Pre-HD & $11(100 \%)$ & $0(0 \%)$ & $0.192(\mathrm{NS})$ \\
\hline Non-diab Pre-HD & $6(85.7 \%)$ & $1(14.3 \%)$ & \\
\hline Non-diab Post-HD & $10(100 \%)$ & $0(0 \%)$ & \\
\hline
\end{tabular}

Pre-HD = fistula created before commencing dialysis. Post- HD = fistula created after commencing dialysis. Non-diab $=$ non-diabetic.

Early complications ( $<30$ days) occurred in eight patients $(9 \%)$. Five patients (two thrombosis, two hematoma, one steal) belonged to the one-stage group and three patients (two thrombosis, one hematoma) was in the two-stage group Overall, there was no statistical significance comparing the total

Table4 complications encountered with the respective probability scores.

\begin{tabular}{lccc}
\hline variable & One stage $(\mathrm{n}=25)$ & Two stage $(\mathrm{n}=25)$ & $\mathrm{p}$-value \\
\hline Overall & 9 & 8 & $0.435(\mathrm{NS})$ \\
\hline Infection & 2 & 2 & $0.69(\mathrm{NS})$ \\
\hline Hematoma & 1 & 1 & $0.87(\mathrm{NS})$ \\
\hline Thrombosis & 3 & 2 & $0.23(\mathrm{NS})$ \\
\hline Steal syndrome & 1 & 1 & $0.76(\mathrm{NS})$ \\
\hline Venous hypertension & 1 & 1 & $0.98(\mathrm{NS})$ \\
\hline Stenosis & 1 & 1 & $0.46(\mathrm{NS})$ \\
\hline
\end{tabular}

complication rate between the two groups $(\mathrm{P}$ value 0.435). Table below reports the complications encountered with the respective probability scores. 


\section{DISCUSSION}

BBAVFs are reliable forms of arteriovenous fistulae. ${ }^{(13-17)} \mathrm{A}$ new similar study by Reynolds et al., ${ }^{(5)}$ showed differences in patency between the two methods of creation. They compared 60 one stage with 30 two stage fistulae created at two different sites. They found significant differences in primary patency at one $(61 \%$ vs $88 \%$ : $\mathrm{p}=0.047)$ and two years $(34 \%$ vs $88 \%$ : $p=0.047)$ in favour of the two stage method. They also found significant differences in secondary patency at two years $(41 \%$ vs $94 \%$ : $\mathrm{p}=0.015)$ again in favour of the two stage method.

The results of my research are the same as Reynolds et al, better patency at six week (92\% in two stage vs $88 \%$ in one stage, ) and patency at six months $(96 \%$ in two stage vs $92 \%$ in one stage), but more obvious that the patency is much more better when I create the fistula before the patient start dialysis. The exact causes remain unclear but some authors relate it to better general health in patients before they commence dialysis. However the above mentioned better patency rate in patients who don't start dialysis at the time of creation of AVF encourage the early creation of AVF in patients who will require dialysis. Preservation of the medial anti-brachial cutaneous nerve and the medial cutaneous nerve of the forearm from damage considered good benefit of one stage operation in comparison to two stage operation. These nerves supply sensation to regions in the arm and sit lateral and superficial to the basilic vein and encircle it. In a single stage, the vein is disconnected and freely dissected; no need to sacrifice the nerve. But during the transposition stage of a two stage procedure, these nerves often lock down the vein and oppose the transposition. As such they are sacrificed, and as a result, patients often can experience numbness and pain in the relevant distribution within the arm. ${ }^{(22)}$.

The reported complication rate for BBAVF remains high, between $43 \%$ and $71 \%$. ${ }^{(13,18,19-}$ ${ }^{21)}$ The $53.7 \%$ overall complication rate in this study is in agreement with such findings. Hossny. ${ }^{(18)}$ Showed the complication rate was significantly higher in the two-stage elevation group compared with the one-stage transposition group $(71.4 \%$ vs $28.6 \%$; $\mathrm{P}$ >
.001). Kakkos et al,.$^{(21)}$ however, found the complication rate was significantly higher in the one-stage operation (43\% vs $11 \%$; P < .001). Our study did not show any significant difference in the complication rates between the two procedures $(\mathrm{P}=0.435)$. However, there was a trend toward more thrombosis in the one-stage operation ( $3 \%$ vs $2 \% ; \mathrm{P}=0.23$ ). The limitations of my RCT include its small size, also there was a significantly higher percentage of one stage patients undergoing dialysis at the time of fistula creation compared to two stage patients. However in this clinical situation justifying randomization could be difficult, especially when patients who have started dialysis require vascular access as soon as possible, thus Directing me towards a single stage procedure.

\section{CONCLUSIONS}

This study demonstrates significantly improved primary, and secondary functional patency for the two-stage operation, with a similar complication rate to the one-stage procedure. The superior functional patency of the two-stage procedure noted in this study suggests that the two-stage approach should be the operation of choice for BBAVFs.

\section{REFERENCES}

1 Brescia MJ, Cimino JE, Appel K, Hurwich BJ. Chronic hemodialysis using venipuncture and a surgically created arteriovenous fistula. $\mathrm{N}$ Engl J Med 1966 Nov 17;275(20):1089-92.

2 Arroyo MR, Sideman MJ, Spergel L, Jennings WC. Primary and staged transposition arteriovenous fistulas. J Vasc Surg 2008;47(6):1279-83.

3 B.F. Robertson, G.A. Robertson, L. Khan, Z. Raza . Brachiobasilic Fistula FormationSingle versus Two Stage Procedure. European Journal of Vascular and Endovascular Surgery Volume 45 Issue 6 June/2013:689-92.

4 Dagher F, Gelber R, Ramos E, Sadler J. The use of basilic vein and brachial artery as an A$\mathrm{V}$ fistula for long term haemodialysis. J Surg Res 1976;20:373-6.

5. Reynolds TS, Zayed M, Kim KM, Lee JT, Ishaque B, Dukkipati RB, et al. A comparison between one- and two-stage brachiobasilic arteriovenous fistulas. J Vasc Surg 2011;53:1632-9.

6. Harper SJ, Goncalves I, Doughman T, Nicholson ML. Arteriovenous fistula formation using transposed basilic vein: 
extensive single centre experience. Eur J Vasc Endovasc Surg 2008;36:237-41.

7. Gonzalez E, Kashuk JL, Moore EE, Linas S, Sauaia A. Two-stage brachial-basilic transposition fistula provides superior patency rates for dialysis access in a safety-net population. Surgery2010 Oct;148(4):687-93.

8 Keuter XH, van der Sande FM, Kessels AG, de Haan MW, Hoeks AP, Tordoir JH. Excellent performance of one-stage brachial-basilic arteriovenous fistula. Nephrol Dial Transplant 2005;20(10):2168-71.

9 Rao RK, Azin GD, Hood DB, Rowe VL, Kohl $\mathrm{RD}$, Katz SG, et al. Basilic vein transposition fistula: a good option for maintaining hemodialysis access site options? J Vasc Surg 2004;39(5):1043-7.

10 Ascher E, Hingoran A, Gunduz Y, Yorkovich Y, Ward M, Miranda J, et al. The value and limitations of the arm cephalic and basilic vein for arteriovenous access. Ann Vasc Surg 2001;15(1):89-97.

11 Ayez N, van Houten VA, de Smet AA, van Well AM, Akkersdijk GP, van de Ven PJ, et al. The basilic vein and the cephalic vein perform equally in upper arm arteriovenous fistulae. Eur J Vasc Endovasc Surg 2012 Aug;44(2):227-31.

12 Vrakas G, Defigueiredo F, Turner S, Jones C, Taylor J, and Calder F, A comparison of the outcomes of one-stage and two-stage brachiobasilic arteriovenous fistulas. J Vasc Surg 2013;58:1300-4.)

13- Taghizadeh A, Dasgupta P, Khan MS, Taylor J, Koffman G. Longterm outcomes of brachiobasilic transposition fistula for haemodialysis. Eur J Vasc Endovasc Surg 2003;26(6):670-2.

14- Dahduli SA, Qattan NM, Al-Kuhaymi RA, Al-Jabreen MA, Al-Khader AA. Mobilization and superficialization of basilic vein for brachio basilic fistula. Saudi Med J2002;23(10):1203-5.

15- Keuter XH, van der Sande FM, Kessels AG, de Haan MW, Hoeks AP, Tordoir JH. Excellent performance of one-stage brachialbasilic arteriovenous fistula. Nephrol Dial Transplant 2005;20(10):2168-71.

16- Rao RK, Azin GD, Hood DB, Rowe VL, Kohl RD, Katz SG, et al. Basilic vein transposition fistula: a good option for maintaining hemodialysis access site options? J Vasc Surg 2004;39(5):1043-7.

17- Ascher E, Hingoran A, Gunduz Y, Yorkovich Y, Ward M, Miranda J, et al. The value and limitations of the arm cephalic and basilic vein for arteriovenous access. Ann Vasc Surg 2001;15(1):89-97.

18- Hossny A. Brachiobasilic arteriovenous fistula: different surgical techniques and their effects on fistula patency and dialysis-related complications. J Vasc Surg 2003; 37:821-6.

19- Murphy GJ, White SA, Knight AJ, Doughman T, Nicholson ML. Long-term results of arteriovenous fistulas using transposed autologous basilic vein. $\mathrm{Br} \quad \mathrm{J}$ Surg 2000;87:819-23.

20- Fitzgerald JT, Schanzer A, Chin AI, McVicar JP, Perez RV, Troppmann C. Outcomes of upper arm arteriovenous fistulas for maintenance hemodialysis access. Arch Surg 2004; 139:201-8.

21- Kakkos SK, Haddad GK, Weaver MR, Haddad RK, Scully MM. Basilic vein transposition: what is the optimal technique? Eur J Vasc Endovasc Surg 2010; 39:612.

22- Paulson KA, Gordon V, Flynn L, Lorelli D. Modified two-stage basilic vein transposition for hemodialysis access. Am J Surg 2011 Aug; 202(2):184-7 